information about the concerns and decision-making considerations of constituents. We outline here the key findings from interviews with residents of Ontario, Canada, $(n=40)$ in July and August of 2020 regarding their views, concerns, and intentions with respect to a prospective COVID-19 vaccine. In particular, participants expressed concern about the safety and efficacy of any prospective vaccine that is developed in a short timeframe, despite eagerness to eventually take it. Additionally, participants expressed considerations that, while not directly related to vaccines, nevertheless factored into their attitudes about accepting a possible COVID vaccination. These included how successful governments have managed COVID19 so far, existing relationships with healthcare providers, and how they have assessed their risk of contracting or becoming very ill from COVID-19. Trust in science, regulators, and governments will play a critical role in the successful deployment of a COVID-19 vaccine. Governments and public health institutions can take actions to earn trust. Implementing monitoring programs for long-term adverse effects would measure and potentially mitigate risk of unforeseen effects. Supports that provide financial and social stability during the wait for rigorously tested vaccines may increase trust in governments to act in the best interest of their constituents.

\section{HOW TRUST AND POWER RELATIONS MIGHT SHAPE THE WORK OF INCIDENT INVESTIGATORS IN HEALTHCARE SERVICES}

G Vilanova, J Sandall, A Xyrichis. King's College London, UK

\subsection{6/bmjopen-2021-QHRN.35}

Background Improving the quality of care in maternity services is a significant concern in the United Kingdom and a challenge for many other countries around the world. Little is known about the inner workings and interprofessional dynamics of patient safety teams which are responsible for incident investigations in healthcare services.

Objectives To develop an understanding of the patient safety team's identity as internal incident investigators, and how trust and power relations shape their work inside hospitals.

Method An ethnography carried between October 2019 and March 2020 in a large maternity hospital in Brazil. The researcher made use of non-participant observation, individual semi-structured interviews and institutional reading related to incident investigations. Fourteen professionals agreed to take part in this current study. Thematic analysis was used to identify themes and categories.

Results Eight major categories were identified: 'fear of conflicts', 'no jurisdiction and no boundaries of work', 'lowesteem feeling', 'not ready for including patients into investigations', 'invisible hierarchy position', 'educational identity', 'blurred expectations', 'manipulation of data'. All professionals' categories in this study highlighted broadly similar needs in terms of clarifying the investigator role and identity as a team. Participants also feared of being in trouble during an investigation, and it was not uncommon the practice of incident data manipulation. A key finding of this study relates to professionals perceived needs and how they would like to be supported during the incident investigations, contributing to the current evidence.

Conclusions This study provides insights into how fear and lack of identity influence the internal incident investigators work. The lack of identity as a team and the sense of powerlessness to establish jurisdiction of work led investigators to not trust in themselves and have a perceived sense of useless work when comparing what they do with what they expected they should be doing.

\section{6 'THE TRUTHFULNESS FACTOR': A DIMENSIONAL ANALYSIS OF MORAL CARE AND MATERNAL SUBSTANCE USE}

C Whitney. Stony Brook University School of Nursing, USA

\subsection{6/bmjopen-2021-QHRN.36}

Background Delivering quality maternal-child healthcare is compromised when clinicians moralize pregnant or lactating persons' actions. Clinicians are professionally charged with ensuring quality care delivery. However, they commonly moralize substance use and other similarly stigmatized actions during pregnancy and lactation. As a result, pregnant or lactating persons and their infants experience suboptimal health outcomes. Improving health outcomes in this population necessitates understanding how clinicians come to moralize substance use during pregnancy and lactation. Dimensional analysis in the mode of emergent fit, an interactionist qualitative mode of inquiry.

Objective This study aimed to uncover the circumstances under which clinicians moralize substance use in maternal-child symbiosis.

Methods Dimensional analysis in the mode of emergent fit was used as an interactionist method of inquiry. Fifteen semistructured interviews were conducted with maternal-child health clinicians and data were analyzed according to the method's analytic processes.

Results The findings of this emergent fit dimensional analysis form a situation specific theory, which reveals that clinicians moralize substance use in maternal-child symbiosis when perceived fractured trust in the caring relationship. These circumstances exist within the process of the Moral Energy Reflex, which is driven by the condition of 'The Truthfulness Factor' and results in the consequence of Reflection on Redirection. The condition, process, and consequence of the phenomenon are conceptually bounded within the context of Unacceptability Uncertainty. All of the dimensions of moralizing substance use during maternal-child symbiosis are understood through the perspective of Am I a 'Good Enough' Clinician?

Conclusion Understanding moralization as a process actively formed by the person moralizing and their perceptions of trust, provides important new insight into the clinical phenomenon of moral judgment. These findings suggest directions for future inquiry and offer implications for education, practice, and policy.

\section{$37 \quad$ PUBLIC TRUST IN HEALTHCARE SYSTEMS IN INDIA}

J Yadav. Center of Social Medicine and Community Health, Jawaharlal Nehru University, India

\subsection{6/bmjopen-2021-QHRN.37}

Background Trust in healthcare institutions plays a major role in public health as it reflects patients' compliance with the medical care system and better utilization of the resources 
available. The ongoing COVID-19 pandemic has surfaced the declining trust in both the public and private healthcare systems in India. It warrants the need to understand why public trust in healthcare institutions is deteriorating. Healthcare system in India has changed over the years. It has brought in, the concepts of commercialization and new managerialism. This has changed the relationships of providers and health managers which creates an impact on public trust in the healthcare system. Indian public healthcare system is highly under-resourced and yet is the only resort for a major section of the society, especially the poor. It is widely known to be inefficient in catering to the needs of the public. The private healthcare system on the other hand has grown exponentially and has proved to be highly overprized.

Aim To draw a conceptualization of public trust in healthcare systems in the Indian context. I will be referring to the model of Public Trust in Healthcare given by Felix Gille (2017). In this model, the public sphere, where public trust is shaped by the discourse of shared experiences and perceptions about the healthcare systems, has been centralized.

Methods Qualitative Systemic Review

Current stage of work: Conceptual framework of the research has been completed and review of the articles is under progress.

Expected results Public sphere is cardinal in shaping public trust in healthcare systems. The process of consensus-building in the public sphere is constantly changing, making it dynamic. The communication channels- active, passive and feedback, shaping the public sphere are temporal. The internal changes in the healthcare systems also determine some aspects of trust.

\section{WHO AND WHAT TO TRUST IN A CRISIS? A NARRATIVE EXPLORATION OF PERSONAL AND POPULATION HEALTH THREATS}

S Yardley. Marie Curie Palliative Care Research Department, University College London

\subsection{6/bmjopen-2021-QHRN.38}

Background Healthcare crises demand decision-making under duress. Time-bound judgments, based on imperfect information, must be made while managing expectations of unpredictable outcomes. Trust is vital for all involved.

Experts characteristically use experience-based narratives to draw inferences. Paradoxically, during the Covid-19 pandemic, prevailing social mistrust of 'experts' switched to an urgent demand for expertise when much was unknown or unknowable. Professionals debated what constituted trustworthy evidence while public intolerance of ambiguity grew. Case studies, including auto-ethnography, combined with narrative analysis can be used to explore novel and complex situations with unclear boundaries between phenomenon and context.

Aims

1. Explore how different forms of uncertainty (expertise, limits of medical knowledge, and discerning which is which) impact on trust and decision-making in patient-professional relationships.

2. Compare dynamics of trust and knowledge mediation during Covid-19 with other health threats.

Methods This work (completion Feb 2021) takes a social constructionist approach, applying Labov's framework for narrative analysis to an auto-ethnographic account and purposively selected stories of Covid-19, HIV/AIDS, cancer and dementia from public media sources. The author is a frontline clinician and qualitative researcher. She is critically considering her experiences and the stories as case studies exemplifying shifting meanings of trust.

Results Identified narrative structures provide insights into variable conceptualisations of trust. Elements (e.g. values, duties, expectations) and genres within individual stories illuminate how notions of safety and risk change according to perceived level and immediacy of threat, balanced against ability to identify trustworthy knowledge. Comparisons of how professionals and patients use life experience, personal networks and external evidence sources, and how different forms of uncertainty impact the building or breaking of trust, will be presented.

Conclusions In Covid-19, disruption to usual communication modes changed trust and relational care beyond that experienced in other personal or population health crises. Understanding this may improve future decision-making and communication.

\section{Oral presentations}

\section{Theme: Conceptualising truth and trust in health related contexts and settings}

\section{Day 1: Thursday $18^{\text {th }}$ March $-13.35-14.55$}

\section{DO YOU WANT TO KNOW WHAT PUBLIC TRUST IN THE HEALTHCARE SYSTEM IS ABOUT?}

${ }^{1} \mathrm{~F}$ Gille*, ${ }^{2} \mathrm{~S}$ Smith, ${ }^{2} \mathrm{~N}$ Mays. 'Swiss Federal Institute of Technology Zurich, Switzerland; ${ }^{2}$ London School of Hygiene and Tropical Medicine, UK

10.1136/bmjopen-2021-QHRN.39

Background Public trust is essential for the well-functioning of healthcare systems. Examples of healthcare activities that are heavily dependent on high levels of public trust are vaccination, organ donation, establishment of national health records or acceptance of measures against pandemics. Despite the frequent use of the term in the public sphere and societal interest to maintain high levels of public trust, we have only a limited understanding of what public trust as a concept actually is. This conceptual uncertainty of public trust in the healthcare system poses problems for health care governance and policy making.

Aim We aimed to answer: what is public trust in the healthcare system?

Methods We analysed three English NHS case studies: an analysis of online news with readership comments concerning the care.data initiative; a secondary analysis of interviews about participants' experiences and perceptions of biobanks; and an analysis of public focus groups about perceptions of the 100,000 Genomes Project. Further, we analysed existing conceptual work and trust theory.

Results This resulted in a full conceptual framework of public trust in the healthcare system. The framework constitutes of 16 conceptual, nine framing and two effect themes. Public trust builds on information equally relating to past experiences, present perceptions and future expectations. Public trust legitimises the actions of the healthcare system as well as encourages the public to participate in healthcare-related 